\title{
DESIGN BASED ON ICF \\ THE TRAINING COURSES FOR IN-SERVICE TEACHERS
}

\author{
Laura Sara Agrati \\ Department of Law, Open University 'Giustino Fortunato’ of Benevento (Italy)
}

\begin{abstract}
The bio-psychosocial model is increasingly becoming the reference for the planning/organization of inclusive interventions, in Europe and in the Italian schools. The ICF has been one of the main topics (1. 107/2015) in the last three-year Italian teacher training plan but it requires to change the traditional way of consider and train on the design skill of teachers.

The work presents the procedures, the technique and the early results of three professional training courses evaluation (years 2017-2019). The courses involved 73 in-service teachers in a southern Italian area and aimed to enhance the design skills of Individualized Education Plan (IEP) based on ICF model. According to the Kirkpatrick Model, the evaluation has been conducted on the teachers' 'learnings' and 'transfer' detected through pre-post test and a document analysis of the PEI-ICF produced.

The study highlighted few linguistic and semantic difficulties (alphanumeric codes, meanings of capacity and performance in the reading of the Functional Profiles) and a better teachers' sensitivity to the environmental component of the functioning. It also outlines some procedures in order to evaluate the training 'results', in terms of learning stability.

This offers some useful arguments for the construction of a possible trans-national platform - sharing of practices, data-base - about the training of school teachers on ICF bio-psychosocial model.
\end{abstract}

Keywords: International classification of functioning disability and health, special education, school inclusion, in-service teachers' training.

\section{Introduction - ICF: A gap between theory and teachers' training}

The 'International Classification of Functioning, Disability and Health' (ICF), as a framework for describing the adult health and disability at both individual and population levels, is inspired by a bio-psychosocial model and is officially endorsed by WHO Member States 2001 (WHO, 2001), then adapted to the children and youth (WHO, 2007). The term 'functioning' refers to the neutral interaction between the individual (with a given health condition) and the contextual factors (environmental and personal); it exceeds the traditional concept of 'disability' as 'deficit' in a dynamic relation between four components - Body Functions and Structures, Activities, Participation, Environmental and Personal factors $^{1}$ (v. Figure 1), linked to meaningful relationship and quality of life - Hollenweger, 2014; UNESCO, 1994); it offers a 'new paradigm and taxonomy of human functioning and disability, which can be used to guide holistic and interdisciplinary approaches to assessment and intervention' (Simeonsson, 2009, p. 70).

Figure 1. Structure of ICF (WHO, 2013, p. 18).

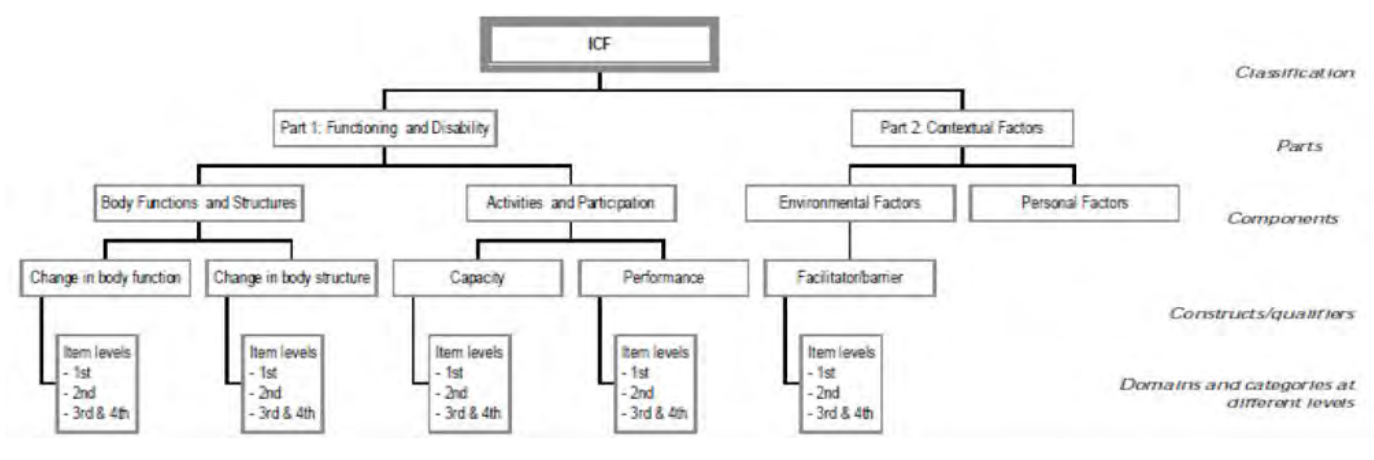

${ }^{1}$ Participation as involvement in a life situation and environmental factors as 'attitudes or physical-social environment in which people live and lead their existence'. 
The ICF framework introduces more specific meanings: 4 levels for qualifying each component (no problem, mild, moderate, complete); alphanumeric codes for summarizing dimensions, chapters, qualifiers ${ }^{2}$; tow important distinctions - between performance (in the current environment) and capacity (in a standard environment) into 'Activity and Participation' and between barriers and facilitators into 'Environmental factors' component (Chiappetta Cajola et al., 2016).

WHO has elaborated numerous explanatory tools useful for creating a common knowledge base for professionals in the medical, psycho-social and educational area involved as trainers and users (Tokunaga, 2008) - checklist, short list, e-learning platform with tools and quizzes for verify. Despite, the ICF bio-psychosocial model is increasingly becoming the reference for the planning/organization of inclusive interventions, mostly in Europe (Sanches-Ferreira et al., 2018; Moretti et al., 2012), however 'there has been relatively little use of the ICF-CY in educational settings and for eligibility decisions about scarce education provision' (Norwich, 2016, p. 10).

Researches show the ICF usefulness for in-depth description of individual and student's (Klang et al. 2016) needs, the development of individualized programs (Sanches-Ferreira et al., 2015), the wide decision-making, a better comparison of specific cases but also the need to train teachers: a. to read the objectives form a more global perspective and on multiple domains (Sanches-Ferreira et al., 2013); b. to assume environment as an indispensable aspect of intervention (Castro et al., 2014). One of the early experiences of professional development in Italy, aimed at design the IEP though the services, parents and school collaboration (Francescutti et al., 2009), found a satisfactory adhesion to the new ICF-based protocols but also difficulties in distinguish roles and responsibilities as well as in assume 'environment' as a category for procedures and materials. Some recent researches on the elaboration of IEP (Meucci et al., 2014) reported teachers' difficulties in using constructs as 'bodily impairments', capacity and participation and in full understanding distinction between barriers and facilitators.

As noted by Norwich $(2016$, p. 10) 'these results suggest (...) that there is a gap between the ICF theory and IEP development practice that raises questions about how the ICF policy innovation has been implemented and adopted' (p. 8) and how teacher training should be enhanced.

\section{Design and objectives - Training on ICF design skill of teachers}

In Italy ICF was introduced as descriptive model and inclusive procedure in 2012 (Minister Decree December 27th 2012; European Commission, 2013) and officially adopted for the development of IEPs in 2016 (D.Lgs. n. 66). After that, Ministry of Education started a sweeping three-year in-service training (1. 107/2015 - 2016-2019) for teachers and support teachers, which integrates contextual and systemic skills - as well as that of the design - within the whole competence framework.

Design competence could be considered a 'hybrid' (Davey, 2013) - ability to effectively connect learning objectives and outcomes and to adapt these to specific needs and context resources - and a 'peculiar' feature (Laurillard, 2012) .

Three training courses were held for in-service teachers - in the south of Italy, years 2017-19 named 'ICF 1', 'ICF2', 'ICF3') - aimed at enhance the design skill of IEP-IC and profiles on specific contents and skills (Table 1) and profiled on four phases of development (Table 2).

In conjunction with the training courses, a more extensive exploratory survey was carried out, based on a sequential mixed-method design (Creswell, Plano Clark, 2007; Cameron, 2009). This paper presents the outcome of the qualitative analysis regarding the knowledge on ICF.

Table 1. Main contents and learning objectives of IEP-ICF training courses.

\begin{tabular}{|l|l|}
\hline Contents: & Learning objectives: \\
\hline Legislation on inclusion, up to the news of Legislative & $\begin{array}{l}\text { use technical language and procedures of ICF model } \\
\text { read a Functional Profile and a PEI-ICF as documents for } \\
\text { sechoe n. } 66 / 2017 \\
\text { Language and articulation of the ICF bio-psychosocial } \\
\text { model (WHO, 2007) }\end{array}$ \\
$\begin{array}{l}\text { Procedures to elaborate Functional Profile and IEP-ICF } \\
\text { and case studies provided }\end{array}$ \\
\hline
\end{tabular}

\footnotetext{
${ }^{2}$ 'The letters b, s, d, and e represent the different components and are followed by a numeric code that starts with the chapter number (one digit), followed by the second level (two digits), as well as third and fourth levels (one extra digit each). For example, the following codes indicate a 'mild' problem in each case' - b2.1 Sensory functions and pain; b210.1 Seeing functions; b2102.1 Quality of vision; b21022.1 Contrast sensitivity - WHO, 2013, p. 17.

${ }^{3}$ The 'designer' socially builds a design model, negotiating his/her own individual knowledge (past experiences, even implicit mental habits - Polanyi, 1967) with shared culture (experiences of colleagues and families, school organization procedures etc.) and sharing a controlled vocabulary/glossary, a specific taxonomy/thesaurus (Rossi, Toppano, 2009).
} 
Table 2. Phases of IEP-ICF training courses.

\begin{tabular}{|l|l|l|}
\hline Learning objectives & Training tool & Focus \\
\hline \multicolumn{2}{|c|}{ Phase I - Information } \\
\hline $\begin{array}{l}\text { Knowledge of the ICF model and language } \\
\text { (alphanumeric codes, technical terms) }\end{array}$ & $\begin{array}{l}\text { Official documents (WHO, 2007; } \\
\text { 2018) } \\
\text { Case-studies }\end{array}$ & $\begin{array}{l}\text { 4-domain model: body functions / } \\
\text { structures; activity and participation; } \\
\text { environmental factors; personal factors }\end{array}$ \\
\hline \multicolumn{2}{|c|}{ Phase II - Deconstruction } \\
\hline $\begin{array}{l}\text { Analysis of traditional IEP models/document } \\
\text { 'by axes' (ICD-10) }\end{array}$ & $\begin{array}{l}\text { Traditional IEP document } \\
\text { Functional diagnosis and } \\
\text { dynamic profile }\end{array}$ & $\begin{array}{l}\text { Difference between IEP by 'axes' and by } \\
\text { 'function' }\end{array}$ \\
\hline \multicolumn{2}{|c|}{ Phase III - Reconstruction } \\
\hline $\begin{array}{l}\text { In a group elaboration of IEP-ICF, based on } \\
\text { case studies and document example }\end{array}$ & $\begin{array}{l}\text { Document example of IEP-ICF, } \\
\text { Functional Profile, Class } \\
\text { programs }\end{array}$ & $\begin{array}{l}\text { Integration between Functional profile, } \\
\text { Individual project, IEP-ICF, Class } \\
\text { programs }\end{array}$ \\
\hline \multicolumn{2}{|l|}{$\begin{array}{l}\text { Phase IV - Construction } \\
\text { personal experience and teaching practice }\end{array}$} & \multicolumn{1}{|c|}{\begin{tabular}{l} 
Document's adaptation to specific cases \\
\hline
\end{tabular}}
\end{tabular}

\section{Methods - Learnings of training though pre-post test}

According to the Kirkpatrick Model (1996), the results of training intervention has been focused on the teachers': learnings - increase in knowledge, skills, attitudes in participants - detected through an ad-hoc pre-post test on content and knowledge; transfer - if participants utilize learnings at work, every-day live etc. ${ }^{4}$ - document-comparative analysis (Bowen, 2009) of the PEI-ICF produced during training and adopted at school.

For learnings it has resorted to an 'ad hoc' test, articulated in n. 10 questions - four closed ended item; it is the adaptation of a validated tool (Francescutti et al., 2009) which detects knowledge on the general function of the ICF (Q.1, Q.2), on qualifiers in alphanumeric codes (Q.3, Q.9, Q.10), on performance and capacity in 'Activities and participation' (Q.5, Q.6, Q.8), on 'Environmental factors' (Q.4, Q.7). It was administered at the end of Information (pre) and Reconstruction (post) phases (see Table 2) and completed anonymously. The teachers - not statistically representative n. 73 - have varied characteristics, regarding seniority average $(4,7)$ and teaching experience in supporting (n. $60-82,2 \%$ ) - see Table 3 .

Table 3. Characteristics of participants.

\begin{tabular}{lrrrr} 
Course & \multicolumn{1}{c}{ ICF1 } & \multicolumn{1}{c}{ ICF2 } & \multicolumn{1}{l}{ ICF3 } & Tot. \\
\hline n. participant & 17 & 14 & 42 & 73 \\
\hline School grade & $\mathrm{I} / \mathrm{P}$ & $\mathrm{I} / \mathrm{P}$ & $\mathrm{I} / \mathrm{P} / \mathrm{M}$ & \\
\hline Seniority average & 3 & 3,5 & 7,5 & 4,7 \\
\hline n. support teachers & 13 & 10 & 37 & 60 \\
$(\%)$ & $(76,50 \%)$ & $(71,4 \%)$ & $(88,1 \%)$ & $(82,2 \%)$ \\
*I $=$ Preschool; P = Primary School; M = Middle School & & &
\end{tabular}

\subsection{Analysis}

Fellows an example of the analysis of the question (Q.5) on relation between performance / environmental factors (as facilitator) / capacity - a detailed presentation of the analysis elsewhere. Analyzing the types of answers, it is possible to attribute discover specific difficulties:

Q.5. Text - 'If a pupil has slight difficulties in reading and is supported by the teacher who merely provides simple help in keeping the attention alive, the qualifiers to be used should be':

Table 4. Analysis of the Q5 answers.

\begin{tabular}{|l|l|l|}
\hline Answer & Text & Type of difficulty \\
\hline $1-$ right & $\begin{array}{l}\text { '1 in performance and } 2 \text { in capacity; support is } \\
\text { to be scored as a mild facilitator }(+1)\end{array}$ & $R=$ right answer \\
\hline $2-$ wrong & $\begin{array}{l}\text { '1 in capacity and } 2 \text { in performance; support is } \\
\text { to be scored as a mild facilitator }(+1)\end{array}$ & $\begin{array}{l}\text { Meanings - inversion of meaning between 'performance' } \\
\text { and 'capacity' } \\
\text { WM = wrong answer for meanings }\end{array}$ \\
\hline $3-$ wrong & $\begin{array}{l}\text { '0 in capacity and } 1 \text { in performance; support is } \\
\text { to be scored as a mild facilitator }(+1)\end{array}$ & $\begin{array}{l}\text { Levels - failure in recognizing qualifier levels } \\
\text { WQ }=\text { wrong answer for qualifiers }\end{array}$ \\
\hline 4 -wrong & 'no support can be scored' & $\begin{array}{l}\text { Logic - failure in recognizing link between 'performance' } \\
\text { /facilitators / 'capacity' } \\
\text { WL = wrong answer for general logic }\end{array}$ \\
\hline
\end{tabular}

${ }^{4}$ Other levels are: 1. Reaction - how participants react to the training (e.g., satisfaction, feelings); 4. Results if there is a positive impact on the participants' organization (Kirkpatrick, 1996). 
Figure 2. Distribution pre-post and movement of WL answers.

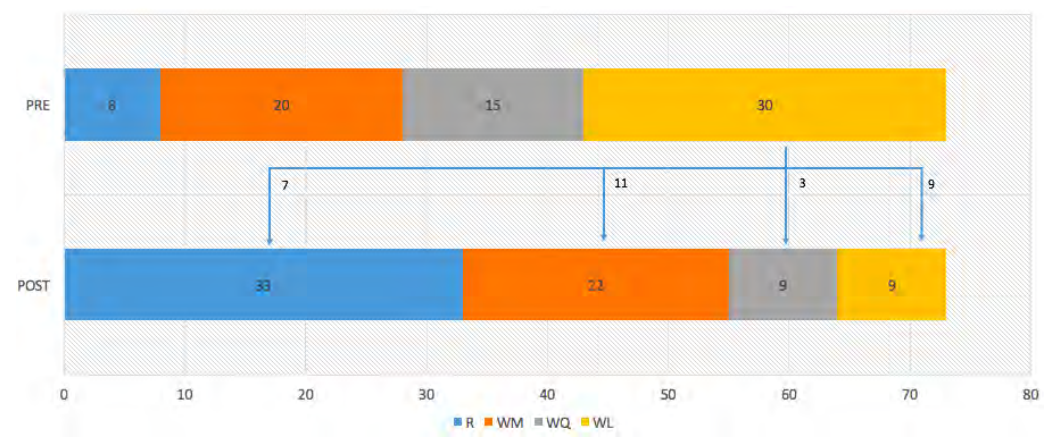

Based on the Q.5's analysis (Figure 2) - chosen only as an example - it is found that training had a general positive impact on learning (Kirkpatrick, 1996) - the pre-post comparison stated that:

a. increase in the right answers (Rpost - Rpre $=+25$ )

b. incorrect answers persist on the meaning of the terms (WMpost - WMpre $=+2)$

c. wrong answers on qualifiers decrease (WQpost - WQpre $=-7$ )

d. the wrong answers about logic decreases (WLpost - WLpre = - 21) - note also the movement of wrong answers on logic $(\mathrm{WLpre}=30)$ : redistributed $($ Rpost $=7$; WMpost $=11$; WQpost $=3)$ while remaining (WLpost $=9$ ).

\section{Discussion}

From a descriptive point of view, the participants understand the difference barrier - facilitator starting from the case provided - R, WM, WRpre -, however at the operational level they manifest two types of difficulties: a. logical-semantic: the difference between capacity ('standard' environment) and performance ('current' environment) and the function performed by environmental factors within this relationship are difficult to gasp - n. WLpre; b. graphic-linguistic: in coding the environmental factors, participants easily distinguish facilitators (with graphic notation '+') not barriers (graphic notation '.'), confused with the performance and capacity qualifiers.

It is appropriate to highlight, also, an aspect of the course' structure. In phase I Information (Table 2), environmental factors were presented as 'attitudes or physical-social environment in which people live and lead their existence' (WHO, 2007) that influence the functioning and disabilities from the outside and in the form of facilitating $(+)$ or impeding (-) impact on performance and capacity. Given that clarity, compared to Q.5, a high number of correct answers in the pre-test would have been expected, at the end of phase I; instead the increase $(\mathrm{R}=+25)$ occurred in the post-test, at the end of phase III. This suggests that not the knowledge learned in phase I was affected by the increase but the skills exercised in II and III phases (analysis of case studies, IEP-ICF documents example); it leads to reconsider 'learnings' as object of evaluation according to the Kirkpatrick model: in order to encourage understanding of IEP-ICF by teachers, it does not seem useful to separate declarative (phase I) and procedural (phase III) knowledge.

\section{Conclusions}

The complete analysis - answers to the pre-post test as well as Document analysis in the triangulation phase (Fig. 2) - will be provided elsewhere. However, it is already possible to deduce useful information for the training' organization on IEP-ICF design - some procedures in order to evaluate the training 'results', in terms of learnings stability (Kirkpatrick, 1996).

As already noted in previous research, teachers should be supported, in general regarding the ICF model, in integrating environmental factors within students' learning objectives (Castro et al., 2014) and, regarding the elaboration of IEP, in better distinguishing capacity/participation and barriers/facilitators (Raggi et al., 2013). Our analysis is highlighting a teachers' better sensitivity to the environmental component of the functioning, form the semantic point of view (alphanumeric codes, meanings of capacity and performance in the reading of the Functional Profiles) but also a logic difficulty regards the relationship performance / environmental factors (such as 'barriers' / 'facilitators') / capacity. The well known graphic model used in phase I (Tab. 2) - presenting 'Activity and Participation' and 'Environmental factors' (Fig. 1) not so related -, is functional for understanding meanings (declarative knowledge) but not relationships (procedural knowledge). The exemplary PEI-ICF used in phase III Reconstruction (Tab. 2) - which directly describe this relationship seem more useful for the learnings of teachers, in terms of knowledge and skills. 
From the comparison with other research and teachers' training experiences, similar difficulties emerge although at different levels: this consideration would be enough to wish a possible trans-national platform, about teachers' training on ICF bio-psychosocial model, that shares practices, difficulties and hypotheses of solution and that contributes to the development of common knowledge

\section{References}

Bowen, G.A. (2009). Document Analysis as a Qualitative Research Method. Qualitative Research Journal, 9(2), 27-40.

Cameron, R. (2009). A sequential mixed model research design: design, analytical and display issues, International Journal of Multiple Research Approaches, 3(2), 140-152.

Castro, S., Pinto, A. \& Simeonsson, R. J. (2014). Content analysis of Portuguese individualized education programmes for young children with autism using the ICF-CY framework. European Early Childhodd Education Research Journal, 22, 91-104.

Chiappetta Cajola L. \& Chiaro M., Rizzo A. L. (2016). The use of ICF-CY in Italian school and Evidence Based Education approach: data and research perspectives. Italian Journal of Special Education for Inclusion, 4(2), 73-96.

Creswell, J. \& Plano Clark V. (2007). Designing and Conducting Mixed Methods Research. Thousand Oaks (Ca): Sage.

Davey, R. (2013). The professional identity of teacher educators: Career on the cusp. London: Routledge.

Francescutti, C. \& Fusaro G., Leonardi M. (2009). Italian ICF training programs: describing and promoting human functioning and research. Disabilitity \& Rehabilitaton, 31, 46-9.

Hollenweger, J. (2014). Definition and Classification of Disability. New York: UNICEF.

Kirkpatrick, D. (1996). Revisiting Kirkpatrick's four-level-model. Training \& Development, 1, 54-57.

Laurillard, D. (2012). Teaching as a design science. Building pedagogical patterns for learning and technology. New York-London: Routledge.

Meucci, P., Leonardi, M., Sala, M., Martinuzzi, A., Russo, E., Buffoni, M., et al. (2014). A survey on feasibility of ICF-CY use to describe persisting difficulties in executing tasks and activities of children and adolescent with disability in Italy. Disabil. Health. Journal. 7, 433-441.

Moretti, M., Alves, I., Maxwell, G. (2012). A systematic literature review of the situation of the international classification of functioning, disability, and health and the international classification of functioning, disability, and health-children and youth version in education: a useful tool or a flight of fancy? American Journal of Physical Medicine \& Rehabilitation, 91, 103-117.

Norwich, B. (2016). Conceptualizing special educational needs using a biopsychosocial model in England: the prospects and challenges of using the international classification of functioning framework. Frontier in Education, 1, 1-29.

Polanyi, M. (1967). The tacit dimension. New York: Doubleday Anchor.

Rossi P.G. \& Toppano E. (2009). Progettare nella società della conoscenza. Roma: Carocci.

Sanches-Ferreira M. \& Silveira-Maia M., Alves S., Simeonsson R.J. (2018). Conditions for Implementing the ICF-CY in Education: The Experience in Portugal. Frontier in Education. 3:20.

Sanches-Ferreira, M. \& Simeonsson, R. J., Silveira-Maia, M., Alves, S. (2015). Evaluating implementation of the international classification of functioning, disability and health in Portugal's special education law. International Journal of Inclusive Education, 19, 457-468.

Simeonsson, R. J. (2009). ICF-CY: a universal tool for documentation of disability. Journal of Policy and Practice in Intellectual Disabilities. 6, 70-72.

Tokunaga, A. (2008). The attempt of the practical application of international classification of functioning, disability, and health (ICF) as a tool for collaboration among various professionals: a perspective on its applicability to "individualized educational support plan". NISE Bull. 9, 1-26.

UNESCO (1994). The Salamanca Statement and Framework for Action on Special Needs Education. Salamanca, Spain: UNESCO.

WHO (2001). International Classification of Functioning, Disability and Health (ICF). Geneva: WHO.

WHO (2007). International Classification of Functioning, Disability and Health - Version for Children and Youth (ICF-CY). Geneva: WHO.

WHO (2013). How to use the ICF: A practical manual for using the International Classification of Functioning, Disability and Health (ICF). Exposure draft for comment. Geneva: WHO. 